\section{Investments in Patient-oriented Research and Population Health Research Are Complementary: Response to Editorial by Gilles Paradis}

\section{Dear Editor:}

Dr. Paradis' editorial in the July/August issue of the $\mathrm{CJPH}^{1}$ is timely because the Canadian Institutes of Health Research (CIHR) strategic plan for patient-oriented research was recently released. ${ }^{2}$ A key point made by Dr. Paradis is the need for greater population health research infrastructure. He asserts that "CIHR should support a massive investment in a multi-decade population health research initiative", arguing that this would be a better option than proposed investments in patient-oriented research.

It is our view that investments in patient-oriented research and population health research are complementary and not mutually exclusive. We need investments in both areas for a stronger health care system and for improvements in the health of Canadians.

Finding the points of intersection between these two arenas of research is essential. Within CIHR, we are doing this in a number of ways. For instance, some of our new Signature Roadmap Initiatives, such as the Community-Based Primary Health Care Initiative, are providing fertile ground for integrating these two perspectives within planned research funding launches. These joint perspectives are also reflected in the request for applications on implementation research to control and prevent hypertension that was announced earlier this year in collaboration with the Global Alliance for Chronic Diseases. ${ }^{3}$

With respect to Dr. Paradis' call for investments in population health infrastructure, substantial progress has been made by CIHR and its partners. Research capacity has been built through initiatives such as Applied Public Health Chairs, Strategic Training Initiatives and Centres for Research Development. ${ }^{4}$ Secondary data analysis is being supported through Regional Data Centres. The field of population health intervention research is advancing through the Population Health Intervention Research Initiative for Canada, international symposia and strategic funding competitions, but ongoing effort is needed to strengthen the theoretical and methodological underpinnings of this field. ${ }^{4}$ A major deliverable of the Strategy for Patient-Oriented Research is further improvement in the population health sphere of research and infra- structure. Finally, cohort studies are being funded through the open operating grants program and strategic initiatives. With respect to the latter, the Canadian Longitudinal Study on Aging, one of CIHR's largest investments in population health infrastructure, will offer a unique platform to allow advances in our understanding of the factors that maintain health and contribute to disability and disease as we age. ${ }^{5}$

Nevertheless, we agree that additional long-term investments in population health research infrastructure, including intervention research, are essential. A recent document on Big Science in Population Health, scheduled for release later this fall and commissioned by CIHR's Institute of Population and Public Health, outlines some important considerations in doing so. But if Canada is to achieve the ambitious agenda laid out by Dr. Paradis, the investments required cannot be met by CIHR alone. As is the case for patientoriented research, a wide range of funders and new models for building and sustaining that infrastructure are needed. With sufficient long-term investments, we can ensure that Canada is a recognized leader in these two critical areas of research and that the benefits of these investments are realized by all Canadians.

\section{Nancy Edwards, ${ }^{1}$ Jean Rouleau, ${ }^{2}$ Robyn Tamblyn, ${ }^{3}$ Yves Joanette ${ }^{4}$}

1. Scientific Director, Canadian Institutes of Health Research-Institute of Population and Public Health (CIHR-IPPH), Ottawa, ON

2. Scientific Director, CIHR-Institute of Circulatory and Respiratory Health, Montreal, QC

3. Scientific Director, CIHR-Institute of Health Services and Policy Research, Montreal, QC

4. Scientific Director, CIHR-Institute of Aging, Montreal, QC

\section{REFERENCES}

1. Paradis G. Patient- or population-oriented research? [Editor's Page] Can Public Health 2011;102(4):243.

2. Canadian Institutes of Health Research. Strategy for Patient-Oriented Research. Available at: http://www.cihr.ca/e/41204.html (Accessed September 12, 2011).

3. CIHR. Team Grant: Implementation Research on Hypertension in Low and Middle Income Countries. Available at: http://www.researchnetrecherchenet.ca/rnr16/viewOpportunityDetails.do?prog=1304\&language=E\&f odAgency=CIHR\&view=browseArchive\&browseArc $=$ true (Accessed September 12, 2011).

4. CIHR. International Assessment for 2011. International Review-CIHR Institute of Population and Public Health. Available at: http://www.cihr.ca/e/ 43679.html\#c3 (Accessed September 12, 2011).

5. Canadian Longitudinal Study on Aging. Available at: http://www.clsa-elcv.ca/ (Accessed September 13, 2011). 